\title{
Infection threshold to estimate Lepeophtheirus salmonis-associated mortality among juvenile pink salmon
}

\author{
Simon R. M. Jones*, N. Brent Hargreaves \\ Pacific Biological Station, Fisheries and Oceans Canada, 3190 Hammond Bay Road, Nanaimo, \\ British Columbia V9T 6N7, Canada
}

\begin{abstract}
A threshold of lethal infection was estimated from previous controlled laboratory exposures to be 7.5 Lepeophtheirus salmonis $\mathrm{g}^{-1}$ for pink salmon Oncorhynchus gorbuscha averaging $<0.7 \mathrm{~g}$. This threshold was used to assess the risk of mortality caused by L. salmonis among pink salmon of the same size class in the Broughton Archipelago, Canada from 2005 to 2008. Virtually all $(\geq 98.9 \%)$ pink salmon collected in late March belonged to this size class, and this proportion declined to $\leq 1 \%$ by early July. The proportion of these small pink salmon with infections equal to or exceeding the threshold declined from 4.5 in 2005 to $0 \%$ in 2008, coincident with an overall decline in parasite prevalence and intensity during this period. In 2005 and 2006, this proportion was greatest in March ( 7.8 and $1.1 \%$, respectively) whereas in 2007, the proportion exceeding the threshold was greatest in May $(2.9 \%)$. In 2008, no infections exceeded the threshold. Parasite development coincided with fish migration through the study area. The declining risk between 2005 and 2008 was possibly related to changes in ocean conditions such as temperature, to changing treatment practices for this parasite on salmon farms, or to changes in the abundance or distribution of non-farmed hosts. The concept of a threshold of $L$. salmonis infection density may be used to assist in the management and conservation of juvenile pink salmon in the Broughton Archipelago region.
\end{abstract}

KEY WORDS: Lepeophtheirus salmonis · Juvenile pink salmon · Infection density · Laboratory · Surveillance

\section{INTRODUCTION}

The salmon louse Lepeophtheirus salmonis is a parasite of marine salmonids throughout the northern hemisphere (Pike \& Wadsworth 1999). Infections are initiated when the free-swimming copepodid settles onto the host and moults through 4 chalimus stages that are each attached via a frontal filament. Subsequent preadult and adult parasitic stages no longer possess the filament and are motile on the host. Damage caused by the parasite results from physical attachment to the host and from feeding on host mucus, skin and blood (Costello 2006). While the importance of host age or size in influencing the outcome of infections has been recognised (Pike \& Wadsworth 1999, Johnson et al. 2004), there has been very little research in this area. Pink salmon Oncorhynchus gorbuscha migrate to the ocean immediately after emerging from gravel spawning beds and may be exposed to the parasite while as small as $\sim 0.3 \mathrm{~g}$. The risk to these post-emergent pink salmon represented by this early exposure remains poorly quantified.

The relationship between the size of juvenile pink salmon and susceptibility to Lepeophtheirus salmonis has been explored in controlled laboratory studies. The parasite is rapidly rejected from pink salmon ranging from 3 to $20 \mathrm{~g}$, and these fish avoid the clinical consequences of infection (Jones et al. 2006a, 2007). This defence mechanism is associated with the expression of pro-inflammatory genes in the skin and head kidney, and functions despite feed deprivation (Jones et al. 2007, 2008a). Thus, competent pink salmon possess an effective innate immunity and are at little risk of infection from exposure. However, a more recent study 
showed that $233 \%$ of $0.3 \mathrm{~g}$ pink salmon died following controlled exposures to $100 \mathrm{~L}$. salmonis copepodids fish $^{-1}$ (Jones et al. 2008b). In that study, parasites were initially observed on all exposed fish, and mortalities occurred between 4 and $26 \mathrm{~d}$ after the exposure. Eighty-one percent of parasites on the dead fish had not developed beyond the chalimus IV stage. In the same study, mortality was reduced or absent following exposure of 0.7 and $2.4 \mathrm{~g}$ pink salmon to the same copepodid challenge level, indicating that the onset of innate immunity against $L$. salmonis occurs at an early age.

The proximity of farmed Atlantic salmon Salmo salar to pink salmon natal streams in the Broughton Archipelago, British Columbia (BC), Canada, has catalysed scientific interest regarding sources of Lepeophtheirus salmonis and its effects on the health of individual pink salmon and their populations. The parasite has been reported on farmed Atlantic salmon, adult and juvenile Pacific salmon (Oncorhynchus spp.) and threespine sticklebacks Gasterosteus aculeatus in this region (Jones \& Nemec 2004, Morton et al. 2004, Jones et al. 2006b, Krkošek et al. 2006, Beamish et al. 2007, Jones \& Hargreaves 2007, Krkošek et al. 2007, Saksida et al. 2007). Considerable differences in parasite abundance on wild and farmed salmon appear to depend on host species, year and geographic location. Differences in the abundance of $L$. salmonis on farmed fish are also related to the production year and to treatment history (Saksida et al. 2007). To date, however, information obtained from these infections has provided little opportunity to assess the extent of impact on the health of pink salmon. In contrast, the controlled laboratory infections have shown the potential for an adverse effect on the smallest pink salmon but indicated that small size alone was not the sole predictor of risk, since the majority of the exposed fish survived. Infection density, expressed as lice $\mathrm{g}^{-1}$ host, has been used to estimate the impact of L. salmonis on Salmo spp. (Bjørn \& Finstad 1997, Finstad et al. 2000, Wagner et al. 2008). The purpose of the present study was to use the laboratory data of Jones et al. (2008b) to estimate a threshold of lethal L. salmonis infection density on postemergent pink salmon. This threshold was used to assess the risk of $L$. salmonis infections on the smallest size classes of pink salmon collected from the Broughton Archipelago from 2005 to 2008.

\section{MATERIALS AND METHODS}

The collection and laboratory maintenance of juvenile pink salmon and their exposure to Lepeophtheirus salmonis were described earlier (Jones et al. 2008b). Pink salmon were exposed to the parasite at mean weights of $0.3,0.7$ or $2.4 \mathrm{~g}$. Following exposure to the parasite, all dead fish were removed from the tank twice daily and measured for fork length, weight, prevalence (\% of fish with infections), intensity (no. of parasites per infected fish) and L. salmonis development.

Methods associated with the annual systematic surveillance for Lepeophtheirus salmonis on juvenile pink salmon and other species in the Broughton Archipelago region of BC are available in Jones et al. (2006b) and Jones \& Hargreaves (2007). From 2005 to 2008, a series of collections 1 mo apart was conducted between March and July. The collection periods were: 1 = late March/early April, 2 = late April/early May, 3 = late May/early June, 4 = late June/early July, $5=$ late July. Sampling in Period 5 was not conducted in 2007 and 2008. Briefly, individual fish were bagged and frozen on-board the seine vessel immediately after capture. Fork length, wet weight and the number and developmental stage of $L$. salmonis were determined for each fish after thawing in the laboratory.

Prevalence and intensity of Lepeophtheirus salmonis were defined according to Bush et al. (1997). Infection density ( $L$. salmonis $\mathrm{g}^{-1}$ ) was calculated for each pink salmon from the intensity of all developmental stages and the weight of the fish. The significance of differences was tested using the Chi-square (prevalence) and Kruskal-Wallis (intensity) tests. A 1000-fold bootstrap procedure in Systat II (Richmond, CA) was used to estimate CIs for the median infection density on the dead laboratory-exposed salmon. CIs were also calculated for prevalence of infection density on wildcaught salmon using Quantitative Parasitology 3.0 (Rozsa et al. 2000). The significance of differences in log-transformed pink salmon weights was tested using ANOVA, and pairwise comparisons were made using Bonferroni-adjusted 2-sample $t$-tests. In all cases, differences were considered significant when $\mathrm{p} \leq 0.05$.

\section{RESULTS}

The 38 pink salmon that died following controlled exposure to Lepeophtheirus salmonis in the study by Jones et al. (2008b) had a mean weight of $0.35 \mathrm{~g}$ (range: $0.13-1.93 \mathrm{~g}$ ) and a mean intensity of 4.7 lice fish $^{-1}$ (range: 1 to 13 lice fish ${ }^{-1}$ ). The infection density

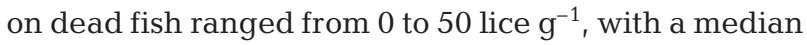
of 14.6 (95\% CI: 7.5 to 22.9) lice $\mathrm{g}^{-1}$. Parasites were absent from 6 dead fish. A value of 7.5 lice $\mathrm{g}^{-1}$, corresponding to the lower $95 \% \mathrm{CI}$ of the median infection density, was chosen as the threshold of lethal infection. Mortality began at $4 \mathrm{~d}$ post-exposure (dpe) and ended at 26 dpe with a mean time to mortality of $16.1 \mathrm{~d}$. In the laboratory study (Jones et al. 2008b), mortality was 
significantly reduced among salmon exposed at mean weights of 0.7 or $2.4 \mathrm{~g}$; consequently, only those infections on wild pink salmon weighing $\leq 0.7 \mathrm{~g}$ were assessed against the threshold.

A total of 14986 wild pink salmon were examined during the study period. Virtually all ( $\geq 98.9 \%$ ) salmon collected during the first period weighed $\leq 0.7 \mathrm{~g}$ and this proportion declined to $\leq 1 \%$ by Period 4 . No pink salmon in this size class were caught in Period 5 (Table 1). The mean weight of pink salmon increased in successive collections in all years (Fig. 1), and mean weight at any time in 2007 was less than that in the corresponding period in all other years ( $\mathrm{p}<0.01$ all cases).

The overall prevalence and mean intensity of Lepeophtheirus salmonis on pink salmon were higher in 2005 compared with other years ( $p<0.004$ in all cases). The prevalence was higher in 2006 compared with 2007 ( $p=0.03)$ or $2008(p<0.001)$ and higher in 2007 compared with 2008 ( $p<0.001$; Table 1). There was no difference in the mean intensity of $L$. salmonis between 2006 and 2007 ( $p=0.90)$ or $2008(p=0.61)$ or between 2007 and $2008(\mathrm{p}=0.55$; Table 1).

Measures of Lepeophtheirus salmonis infection also differed within most years. The prevalence increased between Periods 1 and 2 in 2005, 2006 and 2007 (p < 0.01 in all cases). In 2008, the prevalence was not sig- nificantly different between Periods 1 and 2, but increased in Period 3 and again in Period $4(\mathrm{p}<0.001$ in both cases; Table 1). Trends of decreasing mean intensity observed in 2005 and 2006 were typified by values that were lower in the second compared with the first period examined ( $\mathrm{p}<0.01$ and $\mathrm{p}=0.02$, respectively). In 2007, mean intensity increased between Periods 2 and 3 ( $p<0.01$; Table 1). In 2008, the increase in intensity between Periods 2 and 3 was not statistically significant because of the small number of infected fish. The proportion of motile L. salmonis increased from near 0 in early periods to $\geq 85 \%$ by Period 4 in all years. The proportion of copepodids concurrently decreased to $<5 \%$ of all L. salmonis (Table 1 ).

Infections with densities of $\geq 7.5$ lice $\mathrm{g}^{-1}$ were observed on a total of 60 pink salmon weighing $\leq 0.7 \mathrm{~g}: 43$ $(4.5 \%$ of all pink salmon weighing $\leq 0.7 \mathrm{~g})$ in 2005,9 $(0.8 \%)$ in $2006,8(0.4 \%)$ in 2007 and 0 in 2008 . When calculated by period, these proportions were 7.8 and $1.5 \%$ in 2005 (Periods 1 and 2), 1.1 and $0.5 \%$ in 2006 (Periods 1 and 2), 0.2 and $2.9 \%$ in 2007 (Periods 2 and 3) and 0 in all other periods. The highest median infection density (infected fish only) consistently occurred in the earliest sampling period in all years (Fig. 2), and the median infection densities on all juvenile pink salmon among periods ranged from 0 to 7.5 lice $\mathrm{g}^{-1}$ over $4 \mathrm{yr}$.

Table 1. Oncorhynchus gorbuscha. Estimating the risk of mortality due to Lepeophtheirus salmonis on juveniles. There is a risk of

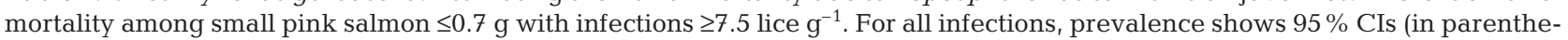
ses), and mean intensity shows the maximum intensity (in parentheses). $\mathrm{N}_{\mathrm{PS}}$, total salmon; $\mathrm{N}_{0.7}$, number of small salmon; $\mathrm{N}_{\mathrm{Th}}$,

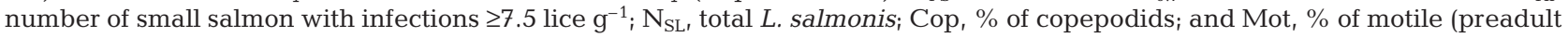
and adult) L. salmonis stages. Values for $\mathrm{N}_{\mathrm{PS}}$ and prevalence in Periods 3, 4 and 5 of 2005 were previously reported in Jones \& Hargreaves (2007). Annual total: total no. of salmon examined; (-) No data. See 'Materials and methods' for definition of periods

\begin{tabular}{|c|c|c|c|c|c|c|c|c|c|}
\hline Year & Period & $\mathrm{N}_{\mathrm{PS}}$ & $\mathrm{N}_{0.7}$ & $\mathrm{~N}_{\mathrm{Th}}$ & $\mathrm{N}_{\mathrm{SL}}$ & Cop & Mot & Prevalence & Intensity \\
\hline \multirow[t]{5}{*}{2005} & 1 & 469 & 464 & 36 & 276 & 13.4 & 1.1 & $15.1(12.1-18.7)$ & $3.9(21)$ \\
\hline & 2 & 1008 & 474 & 7 & 476 & 19.7 & 27.1 & $29.1(26.4-32.0)$ & $1.6(9)$ \\
\hline & 3 & 985 & 15 & 0 & 597 & 21.9 & 47.5 & $31.3(28.4-34.2)$ & $1.9(17)$ \\
\hline & 4 & 858 & 3 & 0 & 393 & 4.6 & 87.5 & $29.3(26.3-32.4)$ & $1.6(8)$ \\
\hline & 5 & 562 & 0 & 0 & 100 & 1.0 & 95.0 & $13.3(10.8-16.4)$ & $1.3(3)$ \\
\hline Annual total & & 3882 & 956 & 43 & 1842 & 15.3 & 46.4 & $25.7(24.4-27.1)$ & $1.9(21)$ \\
\hline \multirow[t]{5}{*}{2006} & 1 & 644 & 640 & 7 & 120 & 40.0 & 6.7 & $11.8(9.5-14.6)$ & $1.6(5)$ \\
\hline & 2 & 864 & 419 & 2 & 282 & 4.6 & 34.8 & $21.0(18.3-23.8)$ & $1.6(7)$ \\
\hline & 3 & 1385 & 37 & 0 & 229 & 3.9 & 81.2 & $12.5(10.9-14.3)$ & $1.3(6)$ \\
\hline & 4 & 600 & 1 & 0 & 135 & 1.5 & 85.9 & $15.8(13.1-19.0)$ & $1.4(6)$ \\
\hline & 5 & 146 & 0 & 0 & 29 & 0 & 89.6 & $15.8(10.5-22.5)$ & $1.3(6)$ \\
\hline Annual total & & 3639 & 1097 & 9 & 795 & 9.1 & 54.6 & $15.1(13.9-16.3)$ & $1.5(7)$ \\
\hline \multirow[t]{4}{*}{2007} & 1 & 566 & 565 & 0 & 21 & 71.4 & 0 & $3.0(1.8-4.7)$ & $1.2(2)$ \\
\hline & 2 & 1351 & 1331 & 3 & 157 & 49.0 & 2.5 & $10.0(8.5-11.7)$ & $1.2(3)$ \\
\hline & 3 & 683 & 174 & 5 & 285 & 13.7 & 37.6 & $27.1(23.9-30.6)$ & $1.6(7)$ \\
\hline & 4 & 876 & 9 & 0 & 196 & 0.5 & 97.6 & $14.3(12.1-16.8)$ & $1.6(6)$ \\
\hline Annual total & & 3476 & 2079 & 8 & 659 & 20.0 & 45.8 & $13.3(12.2-14.5)$ & $1.5(7)$ \\
\hline \multirow[t]{4}{*}{2008} & 1 & 342 & 342 & 0 & 0 & - & - & 0 & 0 \\
\hline & 2 & 774 & 682 & 0 & 7 & 14.0 & 0 & $0.9(0.4-1.9)$ & $1.0(1)$ \\
\hline & 3 & 1656 & 421 & 0 & 73 & 16.0 & 18.0 & $3.8(3.0-4.9)$ & $1.6(3)$ \\
\hline & 4 & 1217 & 2 & 0 & 290 & 2.0 & 96.0 & $15.2(13.3-17.3)$ & $1.5(6)$ \\
\hline Annual total & & 3989 & 1447 & 0 & 370 & 5.1 & 78.6 & $6.4(5.7-7.2)$ & $1.4(6)$ \\
\hline
\end{tabular}



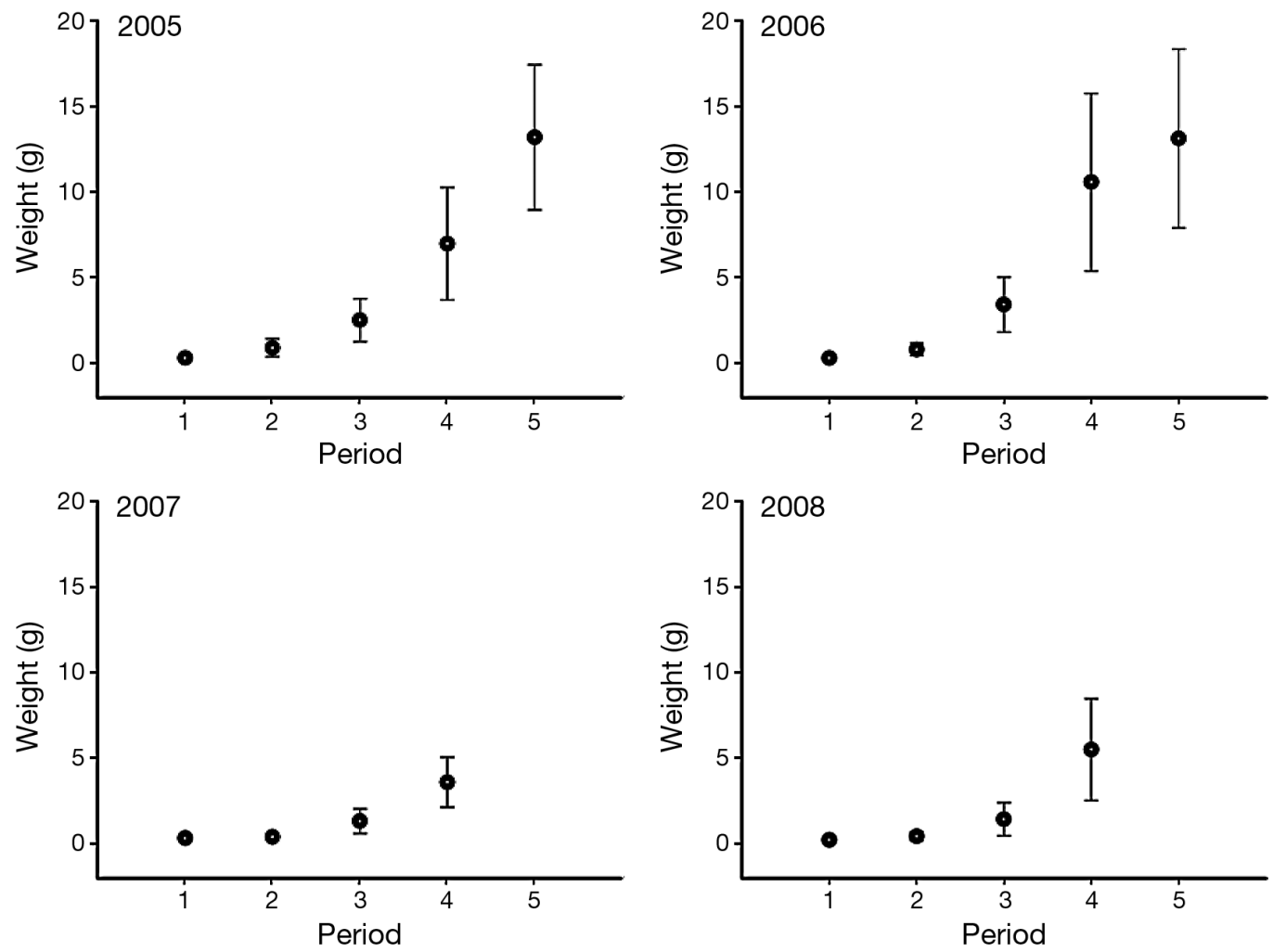

Fig. 1. Oncorhynchus gorbuscha. Mean weight $( \pm \mathrm{SD})$ of juvenile pink salmon collected from the Broughton Archipelago from 2005 to 2008. See Table 1 for sample sizes; see 'Materials and methods' for definition of periods
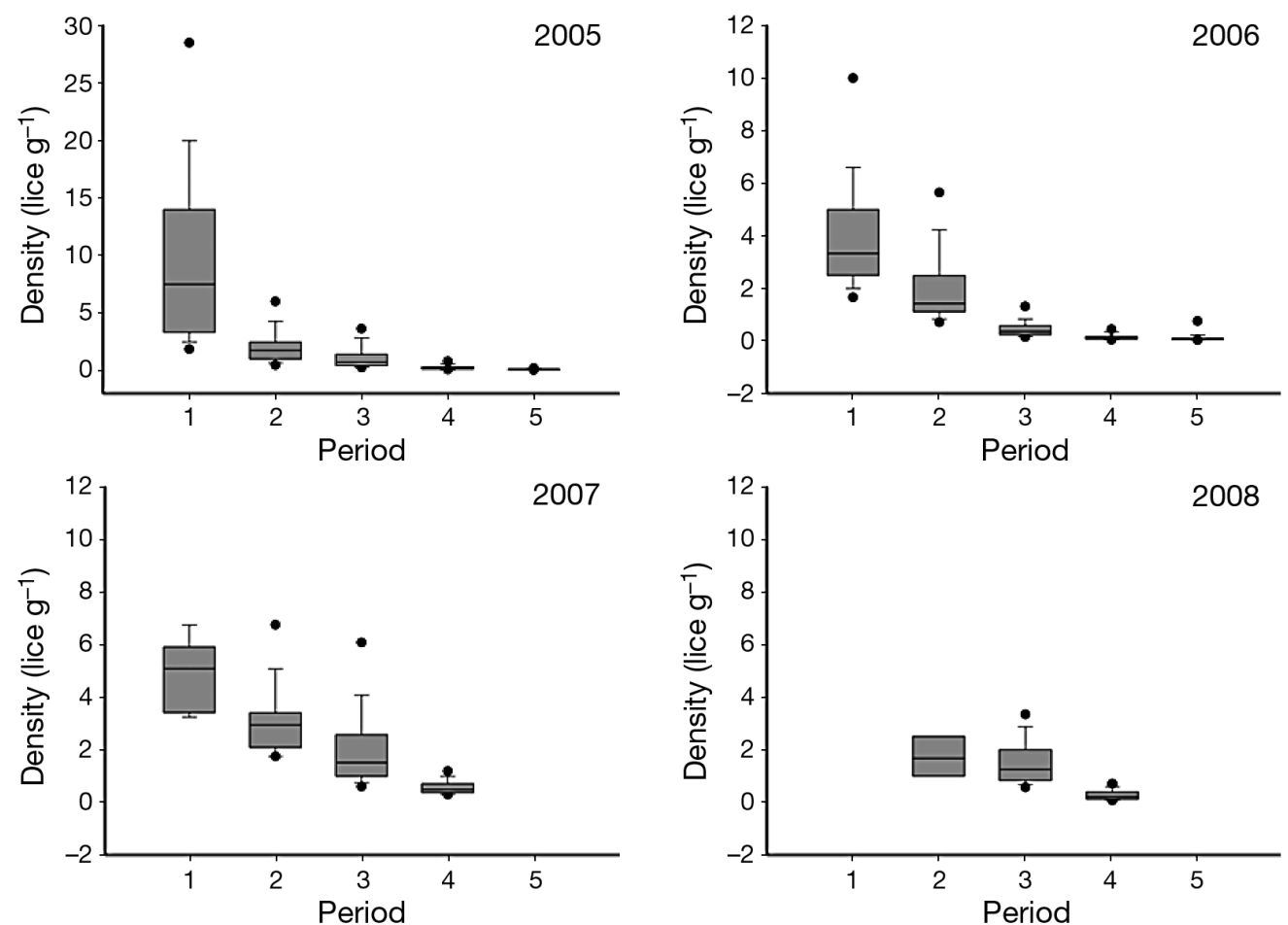

Fig. 2. Lepeophtheirus salmonis infecting Oncorhynchus gorbuscha. Infection densities on juveniles from the Broughton Archipelago. Note that the $y$-axis scale in 2005 differs from those in 2006, 2007 and 2008. Box plots depict median (horizontal line within box), 25th and 75th percentiles (lower and upper edges of box), 10th and 90th percentiles (lower and upper whiskers), and 5th and 95th percentiles $(\bullet)$. See 'Materials and methods' for definition of periods 


\section{DISCUSSION}

Disease is multi-factorial, and isolated observations of parasites on individual fish or within populations are poor predictors of risk. Indeed, the difficulty in predicting disease consequences of parasite infection in wild fish populations has been discussed in some detail by Lester (1984). Severity of the disease caused by the salmon louse Lepeophtheirus salmonis is related to host species, age and condition, as well as to parasite number and developmental stage. By combining intensity and host weight, the infection density may therefore be used as an index of harmful infection (Wagner et al. 2008), particularly among host species such as pink salmon that grow rapidly after migration into the ocean. The surveillance described in the present study coincided closely with the initial migration of the pink salmon into the ocean as demonstrated by the weight distributions observed in each year. Further, while the salmon acquired L. salmonis infections shortly after migration into the ocean, the proportion of copepodids and motile stages indicated that relatively few new infections were acquired in June and July. Laboratory trials (Jones et al. 2008b) showed that early ocean life is the period when pink salmon are at greatest risk of infection from exposure to L. salmonis. Data from these trials were therefore used to estimate the threshold of lethal infection as 7.5 lice $\mathrm{g}^{-1}$. This value represented the lower $95 \%$ CI of median infection densities on fish that died following laboratory exposure and suggested that mortality would be associated with lower densities only $2.5 \%$ of the time. The threshold was only applied to wild pink salmon weighing $\leq 0.7 \mathrm{~g}$ because in the laboratory, mortality occurred among pink salmon exposed at a mean weight of $0.3 \mathrm{~g}$, was significantly reduced among pink salmon exposed at $0.7 \mathrm{~g}$ and did not occur in $2.4 \mathrm{~g}$ salmon (Jones et al. 2008b). Furthermore, all parasite developmental stages were used to estimate risk to pink salmon because most parasites on fish that died following laboratory exposures had not developed beyond the chalimus IV stage.

Some caution should be exercised when assessing natural infections against this threshold because laboratory conditions may differ in several important respects. These include the absence of mixed infections with Caligus clemensi and other disease agents in the laboratory population, the use of a single copepodid exposure in the laboratory compared with multiple possible exposures in nature, and the absence of data on sublethal effects associated with Lepeophtheirus salmonis infection, which may indirectly contribute to mortality. A threshold of 7.5 L. salmonis $\mathrm{g}^{-1}$ for small pink salmon is considerably higher than that estimated for other salmonids: 0.8 and 1.6 chalimus $\mathrm{g}^{-1}$, respectively on Atlantic salmon and sea trout Salmo trutta smolts (Bjørn \& Finstad 1997, Finstad et al. 2000), consistent with the enhanced resistance to the parasite previously reported for pink salmon juveniles (Jones et al. 2007). Additional controlled exposure studies are recommended for pink salmon weighing $<0.7 \mathrm{~g}$ to further refine the effect of size on the relationship between L. salmonis intensity and mortality.

The prevalence and intensity of infections with Lepeophtheirus salmonis of juvenile pink salmon consistently declined between 2005 and 2008, extending the trend previously reported for the Broughton Archipelago in 2004 and 2005 (Jones \& Hargreaves 2007). The proportion of the small pink salmon with infection densities above the threshold underwent a similar decline, suggesting that there was a corresponding reduction in the mortality attributable to the parasite during this period. Indeed, March 2008 was the first collection period since systematic observations began in 2003 in which L. salmonis were not observed on juvenile pink salmon. Interannual differences in ocean characteristics known to influence the abundance and distribution of infective copepodids, such as temperature, salinity and water circulation, are poorly understood for the study area. However, ocean surface temperatures in the study area were warmer in 2004 compared to 2003 and 2005 (Jones \& Hargreaves 2007) and this may have led to an increase in the abundance of infective copepodids in the water column by increasing the developmental rate of larval parasites (Johnson \& Albright 1991). A changing abundance of copepodids coincident with the migration of pink salmon into the ocean may also have been related to the frequency or timing of sea lice treatments used on salmon farms in the study area, as was shown in Loch Shieldaig, Scotland (Penston et al. 2008). The number of treatments with emamectin benzoate in the Broughton Archipelago declined from 0.13 treatments farm ${ }^{-1} \mathrm{mo}^{-1}$ in 2004 to 0.03 treatments farm ${ }^{-1} \mathrm{mo}^{-1}$ in 2007 (S. Saksida pers. comm.), suggesting that common processes regulated the levels of $L$. salmonis both on wild juvenile pink salmon and on farmed salmon. In addition to the abundance of infective copepodids, annual differences in the timing of ocean entry and mean size of juvenile pink salmon, as suggested from weight data in 2007, could influence the outcome of $L$. salmonis infections.

The declining infection densities observed in all years of the survey were largely due to the increasing size of the pink salmon. However, salmon mortality caused by the parasite may also have contributed to the declining densities in years such as 2005 when earlier, more intense infections occurred on smaller fish. The apparent paradox suggested by the collection of pink salmon with infections that exceeded the lethal threshold may be resolved by noting that mortality 
associated with Lepeophtheirus salmonis on laboratory-exposed pink salmon is not instantaneous. Rather, a mean time to death of $16.1 \mathrm{~d}$ following laboratory exposure (Jones et al. 2008b) combined with monthly collections indicated an opportunity to collect living specimens with potentially lethal infections. Mortality due to all causes among juvenile pink salmon along the central coast of $\mathrm{BC}$ ranges from 59 to $77 \%$ during the first $40 \mathrm{~d}$ at sea (Parker 1968), and the historical marine mortality rate of central BC stocks from fry to adult is typically 95\% (Neave 1953, Hunter 1959). More recently, Beamish et al. (2006) showed that marine mortality of Broughton Archipelago pink salmon ranged from $65.8 \%$ in 2004 to $99.9 \%$ in 2002. In the remaining years between 1990 and 2004, mortality was similar to historical levels, ranging from 93.4 to $98.8 \%$. Therefore, while few juvenile pink salmon typically survive to spawn, it is evident that the risk caused by $L$. salmonis closely coincided with the period of high mortality described by Parker (1968). During this period, the epidermis thickens and scales are first formed (Jones et al. 2008b), suggesting a period of generally increased susceptibility to poor environmental conditions, ectoparasite infection and predation (Willette 2001). A comparison of the proportion of small juveniles with supra-threshold infections (0 to $7.8 \%$ ) with the mortality estimate of Parker (1968) suggests that direct mortality caused by L. salmonis was relatively low between 2005 and 2008.

The identification of quantifiable and objective criteria associated with fish size and Lepeophtheirus salmonis infection permitted an assessment of risk to juvenile pink salmon. The concept of a threshold of lethal L. salmonis infection density is proposed to assist in the management and conservation of the susceptible, small-size class pink salmon in coastal ecosystems. Similarly, Wells et al. (2006) recommended a management threshold of $13 \mathrm{~L}$. salmonis fish $^{-1}$ based on the physiological consequences of infection on sea trout post-smolts. While there remains uncertainty concerning all sources of infective L. salmonis copepodids in the Broughton Archipelago, consideration should be given to understanding and mitigating anthropogenic factors that may influence the localised and transient periods of elevated risk associated with the parasite. For example, salmon farm siting criteria that take into consideration local hydrography and wind-driven advection may be adopted to minimise the accumulation of infective copepodids near pink salmon nursery streams. A relationship among these variables has been modelled within a Scottish loch (Murray \& Gillibrand 2005, Gillibrand \& Willis 2007), enhancing the ability to predict distributions and densities of larval $L$. salmonis in the plankton from levels of gravid lice on adjacent farmed salmon (Penston et al. 2008). Alterna- tively, strategic seasonal treatment of farmed salmon, if consistently shown to be associated with sublethal infections on migrating juvenile salmon, may prove effective and practical.

Acknowledgements. Funding for this research was provided by Fisheries and Oceans Canada (FOC), the Aquaculture Collaborative Research and Development Program, Marine Harvest Canada, and the British Columbia Pacific Salmon Forum. Some fish specimens were collected by the Raincoast Research Society. P. Callow of FOC conducted laboratory analysis of the salmon. S. Johnson and M. Trudel of FOC, and B. Nowak of the University of Tasmania provided critical comments on an earlier draft of the manuscript.

\section{LITERATURE CITED}

Beamish RJ, Jones S, Neville C, Sweeting R, Karreman G, Saksida S, Gordon E (2006) Exceptional marine survival of pink salmon that entered the marine environment in 2003 suggests that farmed Atlantic salmon and Pacific salmon can coexist successfully in a marine ecosystem on the Pacific coast of Canada. ICES J Mar Sci 63:1326-1337

Beamish RJ, Neville CM, Sweeting RM, Jones SRM and others (2007) A proposed life history strategy for the salmon louse Lepeophtheirus salmonis in the subarctic Pacific Ocean. Aquaculture 264:428-440

Bjørn PA, Finstad B (1997) The physiological effects of salmon lice infection on sea trout post-smolts. Nord J Freshw Res 73:60-72

Bush AO, Lafferty KD, Lotz JM, Shostak AW (1997) Parasitology meets ecology on its own terms: Margolis et al. revisited. J Parasitol 83:575-583

Costello MJ (2006) Ecology of sea lice parasitic on farmed and wild fish. Trends Parasitol 22:475-483

- Finstad B, Bjørn PA, Grimnes A, Hvidsten NA (2000) Laboratory and field investigations of salmon lice Lepeophtheirus salmonis (Krøyer) infestation on Atlantic salmon Salmo salar L. post-smolts. Aquacult Res 31:795-803

Gillibrand PA, Willis KJ (2007) Dispersal of sea louse larvae from salmon farms: modelling the influence of environmental conditions and larval behaviour. Aquat Biol 1: 63-75

Hunter JG (1959) Survival and production of pink and chum salmon in a coastal stream. J Fish Res Board Can 16: 835-886

Johnson SC, Albright LJ (1991) Development, growth and survival of Lepeophtheirus salmonis (Copepoda: Caligidae) under laboratory conditions. J Mar Biol Assoc UK 71: 425-436

Johnson SC, Treasurer JW, Bravo S, Nagasawa K, Kabata Z (2004) A review of the impact of parasitic copepods on marine aquaculture. Zool Stud 43:229-243

Jones SRM, Hargreaves NB (2007) The abundance and distribution of Lepeophtheirus salmonis (Copepoda: Caligidae) on pink Oncorhynchus gorbuscha and chum O. keta salmon in coastal British Columbia. J Parasitol 93: $1324-1331$

Jones SRM, Nemec A (2004) Pink salmon action plan: sea lice on juvenile salmon and some non-salmonid species in the Broughton Archipelago in 2003. Canadian Science Advisory Secretariat Research Document 2004/105. Fisheries and Oceans Canada, Nanaimo

> Jones SRM, Kim E, Dawe S (2006a) Experimental infections with Lepeophtheirus salmonis (Krøyer) on threespine 
sticklebacks Gasterosteus aculeatus L. and juvenile Pacific salmon Oncorhynchus spp. J Fish Dis 29:489-495 Jones SRM, Prosperi-Porta G, Kim E, Callow P, Hargreaves NB (2006b) The occurrence of Lepeophtheirus salmonis and Caligus clemensi (Copepoda: Caligidae) on threespine stickleback Gasterosteus aculeatus in coastal British Columbia. J Parasitol 92:473-480

Jones SRM, Fast MD, Johnson SC, Groman DB (2007) Differential rejection of Lepeophtheirus salmonis by pink and chum salmon: disease consequences and expression of proinflammatory genes. Dis Aquat Org 75:229-238

Jones SRM, Fast MD, Johnson SC (2008a) Influence of reduced feed ration on Lepeophtheirus salmonis infestation and inflammatory gene expression in juvenile pink salmon. J Aquat Anim Health 20:103-109

> Jones S, Kim E, Bennett W (2008b) Early development of resistance to the salmon louse Lepeophtheirus salmonis (Krøyer) in juvenile pink salmon Oncorhynchus gorbuscha (Walbaum). J Fish Dis 31:591-600

Krkošek M, Lewis MA, Morton A, Frazer LN, Volpe JP (2006) Epizootics of wild fish induced by farm fish. Proc Natl Acad Sci USA 103:15506-15510

Krkošek M, Ford JS, Morton A, Lele S, Myers RA, Lewis MA (2007) Declining wild salmon populations in relation to parasites from farm salmon. Science 318:1772-1775

Lester RJG (1984) A review of methods for estimating mortality due to parasites in wild fish populations. Helgol Meeresunters 37:53-64

Morton A, Routledge R, Peet C, Ladwig A (2004) Sea lice (Lepeophtheirus salmonis) infection rates on juvenile pink Oncorhynchus gorbuscha and chum Oncorhynchus keta salmon in the nearshore marine environment of British Columbia, Canada. Can J Fish Aquat Sci 61:147-157

Editorial responsibility: David Marcogliese, Montreal, Québec, Canada
Murray AG, Gillibrand PA (2006) Modelling salmon lice dispersal in Loch Torridon, Scotland. Mar Pollut Bull 53: 128-135

Neave F (1953) Principles affecting the size of pink and chum salmon populations in British Columbia. J Fish Res Board Can 9:450-491

Parker RR (1968) Marine mortality schedules of pink salmon of the Bella Coola River, central British Columbia. J Fish Res Board Can 25:757-794

Penston MJ, Millar CP, Zuur A, Davies IM (2008) Spatial and temporal distribution of Lepeophtheirus salmonis (Krøyer) larvae in a sea loch containing Atlantic salmon Salmo salar L. farms on the northwest coast of Scotland. J Fish Dis 31: 361-371

Pike AW, Wadsworth SL (1999) Sealice on salmonids: their biology and control. Adv Parasitol 44:233-337

Rozsa L, Reiczigel J, Majoros G (2000) Quantifying parasites in samples of hosts. J Parasitol 86:228-232

Saksida S, Constantine J, Karreman GA, Donald A (2007) Evaluation of sea lice abundance levels on farmed Atlantic salmon Salmo salar L. located in the Broughton Archipelago of British Columbia from 2003 to 2005. Aquacult Res 38:219-231

Wagner GN, Fast MD, Johnson SC (2008) Physiology and immunology of Lepeophtheirus salmonis infections of salmonids. Trends Parasitol 24:176-183

Wells A, Grierson CE, MacKenzie M, Russon IJ and others (2006) Physiological effects of simultaneous, abrupt seawater entry and sea lice (Lepeophtheirus salmonis) infestation of wild, sea-run brown trout Salmo trutta smolts. Can J Fish Aquat Sci 63:2809-2821

Willette TM (2001) Foraging behavior of juvenile pink salmon Oncorhynchus gorbuscha and size-dependent predation risk. Fish Oceanogr 10(Suppl 1):110-131

Submitted: September 19, 2008; Accepted: February 3, 2009 Proofs received from author(s): March 30, 2009 